\title{
sciendo
}

Transport and Telecommunication, 2021, volume 22, no. 1, 98-108

Transport and Telecommunication Institute, Lomonosova 1, Riga, LV-1019, Latvia

DOI 10.2478/ttj-2021-0008

\section{A MODEL OF SYSTEMS DYNAMICS FOR PHYSICAL FLOW ANALYSIS IN A DISTRIBUTION SUPPLY CHAIN}

\author{
Kahina Hamoudi ${ }^{*}$, Ahmed Bellaouar ${ }^{2}$, Romain Petiot ${ }^{3}$ \\ ${ }^{1,2}$ Laboratoire Ingénierie des Transports et environnement, \\ Université des Frères Mentouri- Constantine1, 25000 Constantine, Algérie \\ *Corresponding author: kahina.hamoudi@umc.edu.dz \\ ${ }^{3}$ Univ. Perpignan Via Domitia, ART-Dev, \\ UMR 5281, F-66860, Perpignan, France
}

\begin{abstract}
This article proposes a model of systems dynamics for the analysis and study of physical flows in a distribution logistics chain. The proposed model is a decision support tool that allows testing several scenarios in order to study the behavior of physical flows within a supply chain depending on the inventory and transport costs and taking into consideration the environmental issues through the integration of a $\mathrm{CO}_{2}$ tax in transport costs. The developed model can be used to analyze various scenarios and perform various "what-if" analyzes, as well as to answer questions about the long-term operation of distribution chains. The results show that logistic decisions and strategies taken at the supply chain level influence inventory and transport costs. They show also that the model is a well decision-support tool for calculating and analyzing transport and inventory costs. We first expose the methodology and the literature review. Next, we present in detail the structure of the model consisting of the causal loops diagram and stock and flow diagram. Finally, we discuss the results of the model.
\end{abstract}

Keywords: inventory cost; logistic chain; system dynamics; transport cost

\section{Introduction}

A supply chain is a network of facilities and distribution entities (suppliers, manufacturers, distributors, retailers) that perform functions of supply of raw materials, the transformation of raw materials into intermediate and finished products and distribution of finished products to customers (Sarimveis et al., 2008). The importance of controlling physical flows in a logistics chain to minimize logistics costs and to maintain a certain level of service quality is the goal of any company. The dependence of the supply chain on efficient and well-organized transport infrastructures and technologies explains the importance of transport in logistics. Growing environmental awareness will force states to introduce new laws that will guide supply chains to a new competitive environment. A complete model for tracking the freight flow in a supply chain through the joint analysis of transport and inventory costs is therefore required. The increasing complexity of logistics chains is driving researchers to develop techniques that allow for better analysis of the system. Systems dynamics modeling is one of the methods and approaches used to understand and study the different phenomena and problems of the supply chain.

The System Dynamics (SD), or Industrial Dynamics as its founder has named it, is a modeling technique that was created at MIT (Massachusetts Institute of Technology) by Jay W. Forrester in the 1950s. It allows modeling the structure of a complex system over time to understand and analyze its behavior. It is arobust methodology rooted in systems theory, cybernetics, information science, organizational theory, feedback control theory, military games and tactical decision-making (Abbas and Bell, 1994). Its main function is to create computer models that can rationally analyze the structure, interactions and mode of behavior of complex systems of, thus providing a framework for testing strategies and making compromises (Bala et al., 2017). The SD was the first approach that used system concepts and computer simulation to study and analyze complex problems in management (Abbas and Bell, 1994).

Significant progress in supply chain management has been made by treating them as dynamic systems(Jillson et al., 2014). Recent research in the distribution supply chain deals with inventory and transportation costs separately, and most are based on analytical methods that impose restrictive assumptions (Eddoug and Elhaq, 2015). The literature review on the relationship between logistics and transport operations shows the domination of optimization and developed network models in the field of operational research (Aschauer et al., 2015). All approaches have a common research objective: minimizing transportation or logistics costs or maximizing profits. Nevertheless, they only take into 
account some logistics and transport parameters. Therefore, they can be described as "partial models", considering individual parts of complex logistic systems(De Jong et al., 2004).

We propose a model of systems dynamics for the analysis of the freight flows in a distribution chain. The proposed model is a simulation tool that will enable the understanding and analysis of freight flow based on inventory and transport costs and the evolution of the customer order. The model allows understanding the impact of logistics decisions on transportation costs, inventory costs, customer satisfaction and customer order. The model also addresses the environmental issues through the integration of a tax for $\mathrm{CO} 2$ emissions into transport costs.

\section{Literature review}

\subsection{System Dynamics and supply chain}

The analysis of the literature review shows that this approach is widely used in supply chain management. DS's application of modeling to supply chain management has its origins in the industrial dynamic. Angerhofer and Angelides (2000) provide an overview of the research that has used systems dynamics modeling in supply chain management that focuses on inventory decision making and development policies, the amplification of demand, the design and integration of the supply chain, aswell as the management of the international supply chain.

Several other works dealing with issues of planning, supply, inventory and demand amplification in supply chains have been developed. Ge et al.(2004) present the SD approach for the analysis of the bullwhip effect. Based on the developed model, the causes of the dynamic behavior of the system and the sources of amplification from downstream to upstream of the chain are examined. The results show that, although the forecast generates a time lag typically, it is more stable due to its ability to filter highfrequency noises, which is particularly critical in an environment with random demands. Georgiadis et al. (2005) examine the capacity planning policies for a multi-echelon food supply chain with transient flows due to market constraints using SD. The methodology has been implemented for the process of planning the transport capacity of a major supplier of a Greek fast food chain. Roy et al. (2008) used the SD modeling approach in areas related to production-inventory management. The objective of this research is to improve the modeling and validation approach in areas related to the management of productioninventory; mainly encountered in the pharmaceutical and automotive industry using the Euler integration algorithm. Bhattacharjee and Cruz (2015) develop an end-to-end model of a closed-loop supply chain and identify the systemic decision-making process necessary for the economic viability of participants in this chain. Villa et al. (2015) analyzed retailers order decisions based on supplier capacity acquisition delays through an SD approach. Retailers inflate their orders when the supplier faces longer capacity acquisition delays and when orders take longer to be perceived by the supplier.

The objective of every firm is to minimize its costs by providing quality service to its customers. Given the importance of cost control in supply chains, this question is the subject of research for several works. The SD has also been used to address the cost theme in the supply chain. Sachan et al. (2005) modeled the total cost of the supply chain of an Indian grain chain to understand and predict future supply chain outcomes in different situations. The model helps chain members to understand the behavior of the system with respect to various cost elements in different market scenarios. Franco et al. (2015) present an SD model for analyzing the costs and policies of a logistics distribution subcontracting process. The model takes into account the costs before and after the start of the outsourcing operation and their influence on the net value of the process. The model guides contract durations and shows that in the outsourcing process, the largest gain results from periods of low inflation and low interest rates in a stable economy.

Information technology has also been addressed in the SD. Sidola et al. (2012) studied information technologies in supply chains. They analyze the effects of the adoption of information technology on the market share of small and medium-sized enterprises using the SD. This study suggests that an organization should increase its capacity integration rate simultaneously with increasing orders (which increases due to improved information technology capabilities), in order to reduce the accumulated backlog that leads the customer to spend to another manufacturer. Gonul Kochan et al. (2018) develop two conceptual causal loop diagrams; one representing traditional information sharing and the other is a cloud-based in a hospital supply chain. This study compares the performance indicators of the two models: average stock levels, delivery times and unfilled orders. The results show that cloud-based information sharing improves visibility in supply chains, which increases the responsiveness of a hospital.

The integration of both environmental and social objectives with traditional business economic goals, stakeholder integration and feedback flow into the supply chain has been the focus of several studies over the last decade. The SD has shown its efficiency in the field of logistics. It has been chosen 
to be the modeling method in several works that deal with the reverse and sustainable supply chain. Georgiadis and Vlachos (2004) examined the impact of environmental issues on the long-term behavior of a single product supply chain with product recovery using SD. The model provides an experimental simulation tool, which can be used to assess the effect of environmental problems on long-term decisionmaking for collection and remanufacturing activities and product demand. Vlachos et al. (2007) present the development of a dynamic model based on SD for strategic capacity planning for remanufacturing facilities in a reverse supply chain of a single product, taking into account not only economic issues but also environmental ones. The simulation model provides an experimental tool that can be used to evaluate different long-term capacity planning strategies using total supply chain profit as a measure of policy effectiveness. Poles (2013) modeled a production and inventory system for remanufacturing using the SD. The goal was to understand the interaction between physical flows, information flows, and company policies in order to generate the dynamics of the remanufacturing process and to assess effective control strategies to improve system performance. Ghisolfi et al. (2017) presented a model of systems dynamics that assesses the sustainability of supply chains in the use of raw materials due to disposal costs, collection, recycling and return of certain materials to desktops and laptops. The results show that even in the absence of bargaining power, the formalization of waste pickers is done through legal incentives. It is important to ensure that garbage collectors cooperatives have access to a minimum amount, which requires a level of protection against unfair competition with businesses. Sudarto et al. (2017) developed a flexible and long-term planning policy for closed-loop supply chains that takes into account social responsibility. They presented an SD model of a single product supply chain with reverse social logistics responsibility. The conclusions of this study show that the developed policy could be used to address the life cycle with its inherited uncertainty to optimize the performance of the sustainability dimensions.

\subsection{The SD and freight transport}

The freight transportation is one of the essential conditions for the development and economic growth of the countries. Freight transport modeling by systems dynamics has been the research topic of several studies, where each study uses different parameters and indicators depending on the environment and the purpose of the research. The analysis of the studies that applied the SD method to different transport issues showed that it was well adapted to meet the needs of several transport analysis problems (Aschauer et al., 2015).

One of the freight transport models of the SD is the ASTRA model (ASsessment of TRAnsport Strategies), is a systems dynamics model for strategic transport assessment at the European level. It started in 1997 and ended in late 2000. In recent years, ASTRA has been widely used in many research projects to simulate scenarios of energy scarcity, high oil prices, technological investments in the transport sector and the implementation of the measures included in the European transport policy. Concerning a traditional transportation model, ASTRA is less geographically detailed, but it simulates the links between transport demand, economy, the fleet of vehicles and environmental effects(Fiorello et al., 2010). Another study focusing on urban freight transport was conducted by (Thaller et al., 2017). They develop a freight transport simulation based on SD for urban areas. The study presents the qualitative approach of systems dynamics (causal loop diagram), the internal structure of urban freight transport, the stakeholders involved, and their interdependencies with each other.

Transport in a supply chain is usually an intermediary that facilitates the movement of products from a point of origin to a point of destination (Lai et al., 2002). Transportation demand is highly dependent on economic activities and consumption. As the economy grows, production and consumption increase, leading to an increase in transport demand and vice versa (Ruijgrok, 2008). Although strongly related to economic activity, recent studies on the evolution of freight flow show that they also deserve to be studied from the point of view of the evolution of companies and logistics organizations. These are an integral part of companies' strategies and are not without consequences on the freight flow. The relationship between the logistics organization and transport is not clearly established and given the importance of transport in the supply chains, several works dealing with the problems of freight transport in supply chains have been published using different methods and approaches, including SD modeling.

Transport modelling in the supply chain by SD has been little used in research. Gacogne (2003) presented the SANDOMA model, which is a model of systems dynamics that analyzes the interdependencies between logistics organization and freight transport as well as the role of transport costs in logistics organization. The SANDOMA model considers logistics organization as a system, in which multiple interactions with the organization of production and distribution. Two types of scenarios were tested in the model, the first one corresponded to logistic trends, thus to assumptions about increased standardization of production, concentration of central warehouses and growing weight of large 
customers in sales. The simulations of the model made it possible to assert analyzes implicating the increase of the transport distances in the evolutions of the logistics systems, but also to take into account all the phenomena of massification. The results show not only a reduction in the number of transport links in the networks but also increase in the size of the shipment. The second tested scenario corresponded to assumptions of changes in transport prices. The overall results highlighted the importance of the size of consignments in the arbitration involving transport costs and they showed that transport prices would probably have only a slight influence on the lengthening of the distances.

The model limits the specification of merchandise flows from the loader without dealing with the modal choice. The flows were characterized in terms of tons, tons-kilometers, average distances, total distance travelled by the product from its production site to the customer, number of transport links in the networks, and finally the size and frequency of shipping at each level of the distribution networks. The logistics chain was therefore processed from the production sites to the customer, taking into account possible structural changes (concentration of production sites and centralization-prioritization of distribution networks).

Aschauer et al. (2015) presented another SD model for the interdependencies between logistics strategies and freight transport. The developed model allows the complete description and analysis of the system's operations and also takes into account factors related to transport (toll, internalization of $\mathrm{CO} 2$, capacity of the infrastructure). The study shows that the parameters of logistics strategies and transport operations have close relationships. These interdependencies can occur in different ways, and influence the system as a whole directly and indirectly. Transport flexibility, orders frequency, truck loading capacity, cost parameters, and modal shift play an essential role. Depending on the framework, transport flexibility has enormous potential for reducing cost increases. Higher truck loading capacities do not exclude modal shift to rail. Reducing control frequencies does not always lead to higher utilization or better emission and fuel consumption values. Fewer transport distances do not automatically mean fewer costs or emissions. It could be shown that the introduction of carbon dioxide taxes or the aggravation of road capacity also has less influence on the system. The model focuses primarily on the operational parameters of a logistics strategy. Influence through strategic parameters is not studied. Another basic assumption is that inventory costs have also been excluded from the model. System logistics and freight transport could also be influenced by other relevant business parameters (marketing strategies aiming to make the business greener, financial aspects, etc.) that were also excluded from this model.

To conclude this state-of-the-art, we highlighted a large number of studies that have used SD in supply chain management and freight management. Nevertheless, no comprehensive model allows the analysis of the relationship between the supply chain and the freight flow through the freight transport and inventory costs taking into account customer satisfaction and environmental issues. For this reason, we present in this article a full model using SD for the analysis of physical flows in a distribution chain. The developed model is a decision support tool that allows testing several scenarios in order to predict and understand the behavior of all parameters of the distribution supply chain.

\section{Model description}

In this part, we will explain and describe the developed SD model. We will illustrate transparently and unambiguously the model by a causal loop diagram that allows showing the structure and the components of the studied system as well as the feedbacks between them. Next, we present the stock and flow diagram, the initial variables and the constants of the model. We used Vensim software for this model.

\subsection{Causal loops diagram}

Causal loop diagrams play an essential role in developing of the SD model. They simplify its presentation and serve as preliminary sketches of causal hypotheses. These diagrams capture the main feedback mechanisms (Georgiadis et al., 2005), which can be positive or negative. Positive loops reinforce system events and lead to growth, so they tend to reinforce everything that happens in the system. On the other hand, the effect of negative loops is inversely proportional and leads to a change, so they neutralize and oppose the change (Sterman, 2001). Figure 1 shows the causal loop diagram developed based on the literature review presented previously. This diagram illustrates the different relationships and variables studied. We have made some assumptions to reduce the complexity of the model.

The first variable of the diagram is "capacity" that influences "production". An increase in capacity implies an increase in production. Another parameter that influences production is "demand". An increase in demand implies an increase in production. Moreover, an increase in production increased the "order quantity per year" and "inventory" and an increase in inventory, in turn, decreased production. 
The parameters "order quantity per year" and "order cycle frequency "influence" amount per order cycle". An increase in the order quantity per year leads to an increase in the amount per order cycle, and an increase in the order cycle frequency decreased the amount per order cycle.

The "shipment quantity" parameter is influenced by "amount per order cycle" and "shipments" over a given period. A large number of shipments involves a lower shipment quantity and vice versa, and a high amount per order cycle leads to an increase in shipment quantity and influences in turn "inventory". An increase in the number of shipments leads to a decrease in inventory, which implies a decrease in "inventory costs".

The "utilization of trucks" parameter influences "shipments". Low truck utilization involves a high number of shipments. It is influenced by the "truckload capacity" and the "shipment quantity". Small quantities of shipping mean low use of trucks, while high quantities of shipping have a positive impact on truck use (Aschauer et al., 2015).

The "shipments" parameter influences positively the "road utilization rate". A high number of shipments increases the use of the road, which leads to an "average speed" decrease. A decrease in "average speed" leads to an increase in both "transportation lead time" and "transport costs".

"Road distances traveled" are influenced by the percentage utilization of trucks and the distance between the company and the receiver "transport distance". An increase in the distances traveled increases "fuel consumption", which positively influences "transport emissions" and "transportation costs". "transportation costs" are also influenced by "toll costs" and "transport emissions".

The "distribution costs" are influenced by "transportation costs" and "inventory costs". High "inventory cost" and high "transportation costs" lead to an increase in "distribution costs". The increase in distribution costs decreases both "customer satisfaction" and "demand" which leads to a decrease in the "order quantity per year".

This diagram serves as a basis for the transformation into a quantitative stock and flow model.

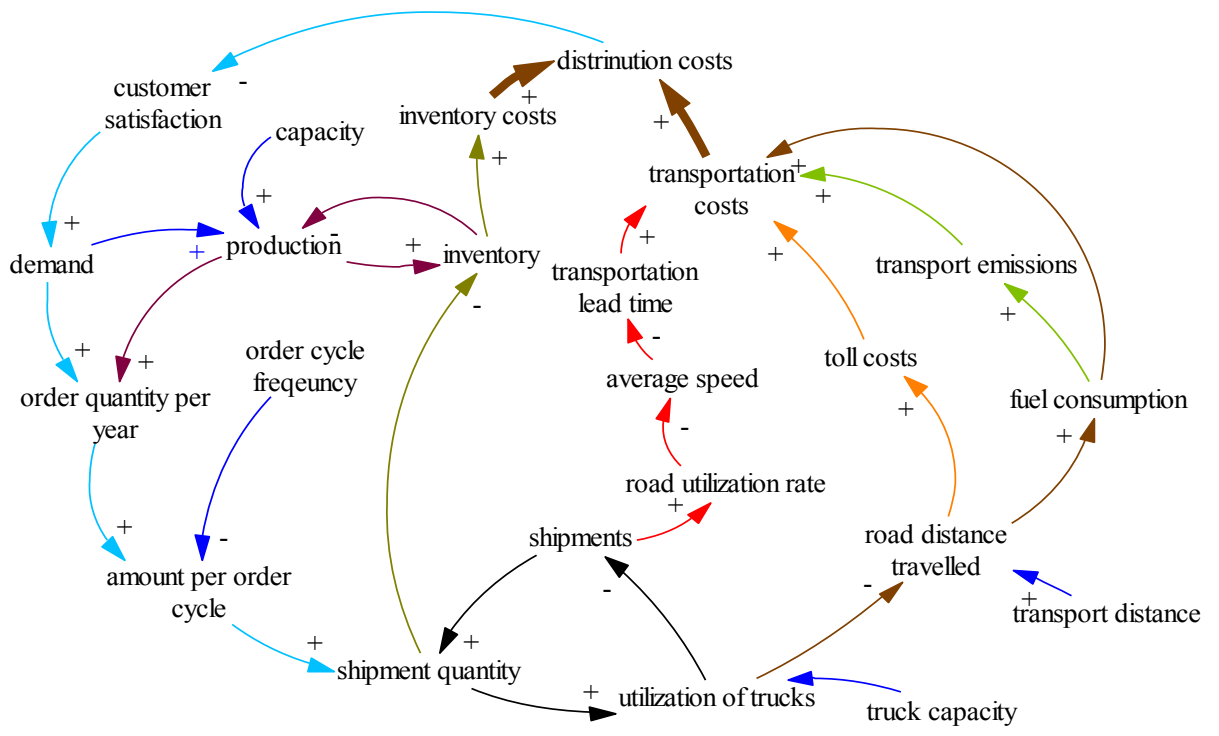

Figure 1. Causal loops diagram

\subsection{Stocks and flow diagram}

This step involves the mathematical development of the model by transferring the causal loop diagram to the stock and flow diagram, which captures the model structure and relationships between variables (Thaller et al., 2017). The stock and flow model constructed is shown in Figure 2.

The stocks represent the state or condition of the system and flows are action variables that modify stocks, increase or decrease their volumes. This representation also contains auxiliaries and connectors, where the auxiliaries have the role of formulating the data and defining the flow equations and the connectors represent the relationships between all the components of the system (Ghisolfi et al., 2017). The stock and flow diagram is easily converted into a system of differential equations, which is then solved by simulation. We define the initial values of stocks and the constants of the model for simulations. The assigned values are shown in Table 1. 


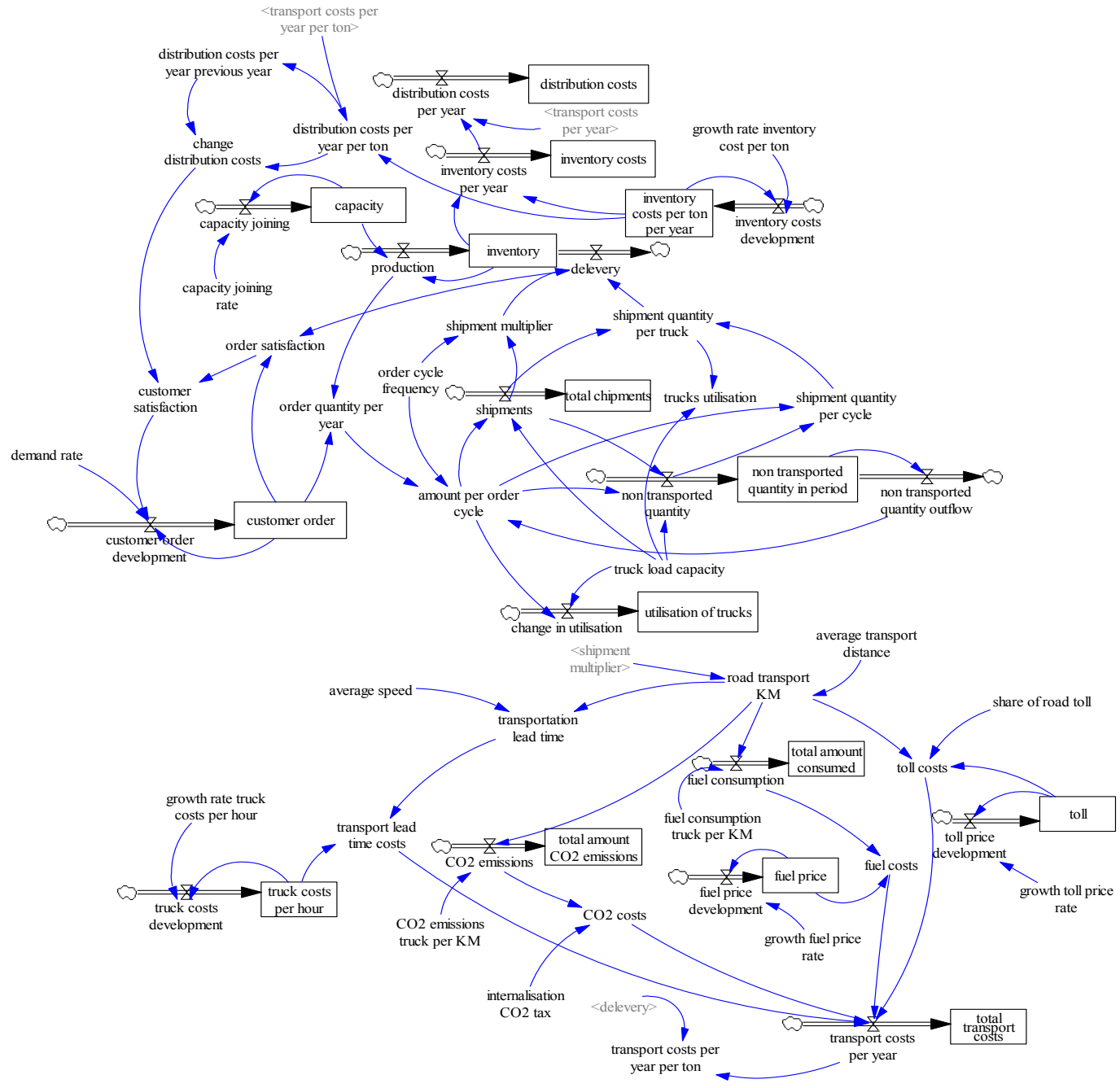

Figure 2. Stock and flow diagram

Table 1. The initial value of stocks and constants

\begin{tabular}{|c|c|c|}
\hline Variables & Values & Units \\
\hline \multicolumn{3}{|l|}{ Constants } \\
\hline average transport distance & 1000 & $\mathrm{~km}$ \\
\hline Capacity joining rate & 5 & $\%$ \\
\hline demand rate & 5 & $\%$ \\
\hline growth fuel price rate & 7 & $\%$ \\
\hline growth rate inventory cost per ton & 5 & $\%$ \\
\hline growth rate truck costs per hour & 5 & $\%$ \\
\hline Growth toll price rate & 5 & $\%$ \\
\hline internalisation $\mathrm{CO} 2$ tax & 0.02 & $€ / \mathrm{kg}$ \\
\hline order cycle frequency & 5 & Order/Year \\
\hline share of road toll & 75 & $\%$ \\
\hline average speed & 80 & $\mathrm{~km} / \mathrm{h}$ \\
\hline truck load capacity & 12 & $\mathrm{t}$ \\
\hline $\mathrm{CO} 2$ emissions truck per $\mathrm{KM}$ & 0.1027 & $\mathrm{~kg} / \mathrm{km}$ \\
\hline fuel consumption truck per KM & $28 / 100$ & $\mathrm{~L} / \mathrm{km}$ \\
\hline \multicolumn{3}{|l|}{ Stocks } \\
\hline Capacity & 300 & $\mathrm{t}$ \\
\hline Customer order & 400 & $\mathrm{t}$ \\
\hline fuel price & 1.4 & $€ / \mathrm{L}$ \\
\hline Inventory & 20 & $\mathrm{t}$ \\
\hline inventory costs per ton per year & 100 & $€ / \mathrm{t}$ \\
\hline truck costs per hour & 30 & $€ / \mathrm{h}$ \\
\hline Toll & 0.5 & $€ / \mathrm{km}$ \\
\hline
\end{tabular}




\section{Simulation results}

To validate the developed model, we processed the results of several tested scenarios by changing the input variables each time. The developed model is a decision support tool in the distribution chain. It allows testing several scenarios and comparing the development of distribution costs and demand.

Our objective in this research is to analyze the relationship between transportation costs, inventory costs, customer satisfaction and customer order. In the basic scenario, we insert the data shown in table 1. These numeric values serve as input data in the SD model. Based on the constants and predefined equations, a 10-year scenario is simulated. We present in this part some scenarios applied to this model and the obtained results.

To analyze the impact of truck loading rates on the distribution chain, we tested the following two scenarios on trucks with a load capacity of $12 \mathrm{t}$.

- $\mathrm{S} 1$ : the truck is shipped only if its loading rate is $50 \%$ or more.

- S2: the truck is shipped regardless of its loading rate.

The observed results (Figure 3) show that distribution costs change from one scenario to another. They are higher when a vehicle is shipped regardless of its loading rate. Inventory costs, however, remain higher in the first scenario where the costs of transport are lower, which influences distribution costs that are therefore less important. The percentage of satisfied customers is slightly high in the first scenario and that goes back to the shipping policy. As for the quantity of emissions, it is higher in the second scenario that is to say when the vehicles are shipped whatever their loading rate.
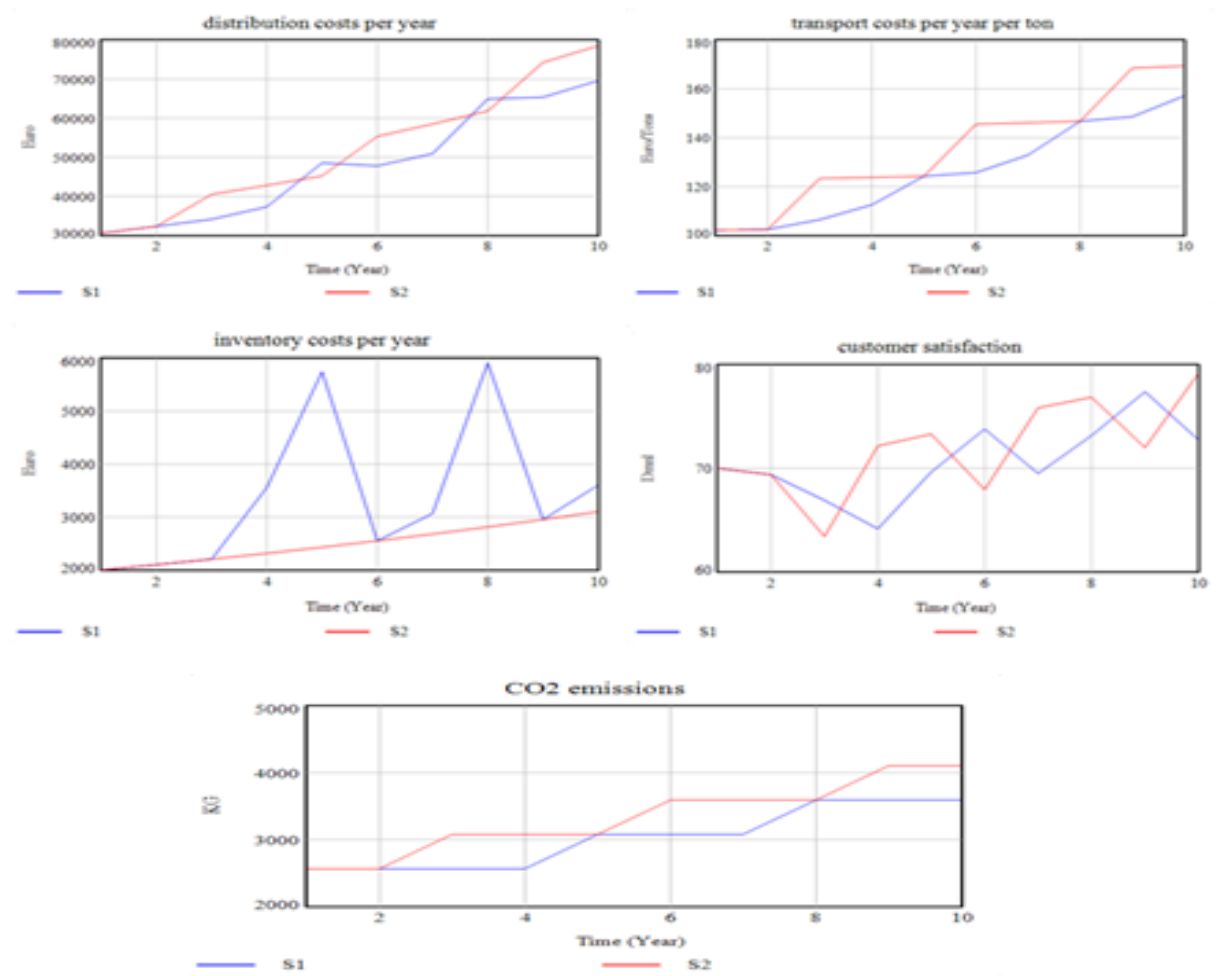

Figure 3. Development of distribution, inventory and transport costs, as well as customer satisfaction and CO2 emissions with the change of the shipping policy

Another test of the model makes it possible to study the impact of the trucks loading capacity on the distribution costs. We simulated the model with $12 \mathrm{t}$ and $6 \mathrm{t}$ vehicles load capacity. The values of the modified input variables are defined in Table 2.

Table 2. The input values of the modified variables

\begin{tabular}{|l|l|l|c|}
\hline \multicolumn{1}{|c|}{ Variables } & \multicolumn{1}{c|}{ Values } & Unites \\
\hline truck load capacity & 6 & 12 & $\mathrm{t}$ \\
\hline CO2 emissions truck per KM & 0.0688 & 0.1027 & $\mathrm{~kg} / \mathrm{km}$ \\
\hline fuel consumption truck per KM & $23 / 100$ & $28 / 100$ & $\mathrm{~L} / \mathrm{km}$ \\
\hline truck costs per hour & 20 & 30 & $€ / \mathrm{h}$ \\
\hline
\end{tabular}


The results (Figure 4) show that the distribution costs are higher in the case where the loading capacity of the trucks is $6 \mathrm{t}$ and that comes down to the transport costs which are very high because of the number of the high shipments. This also leads to an increase in the emission quantity.
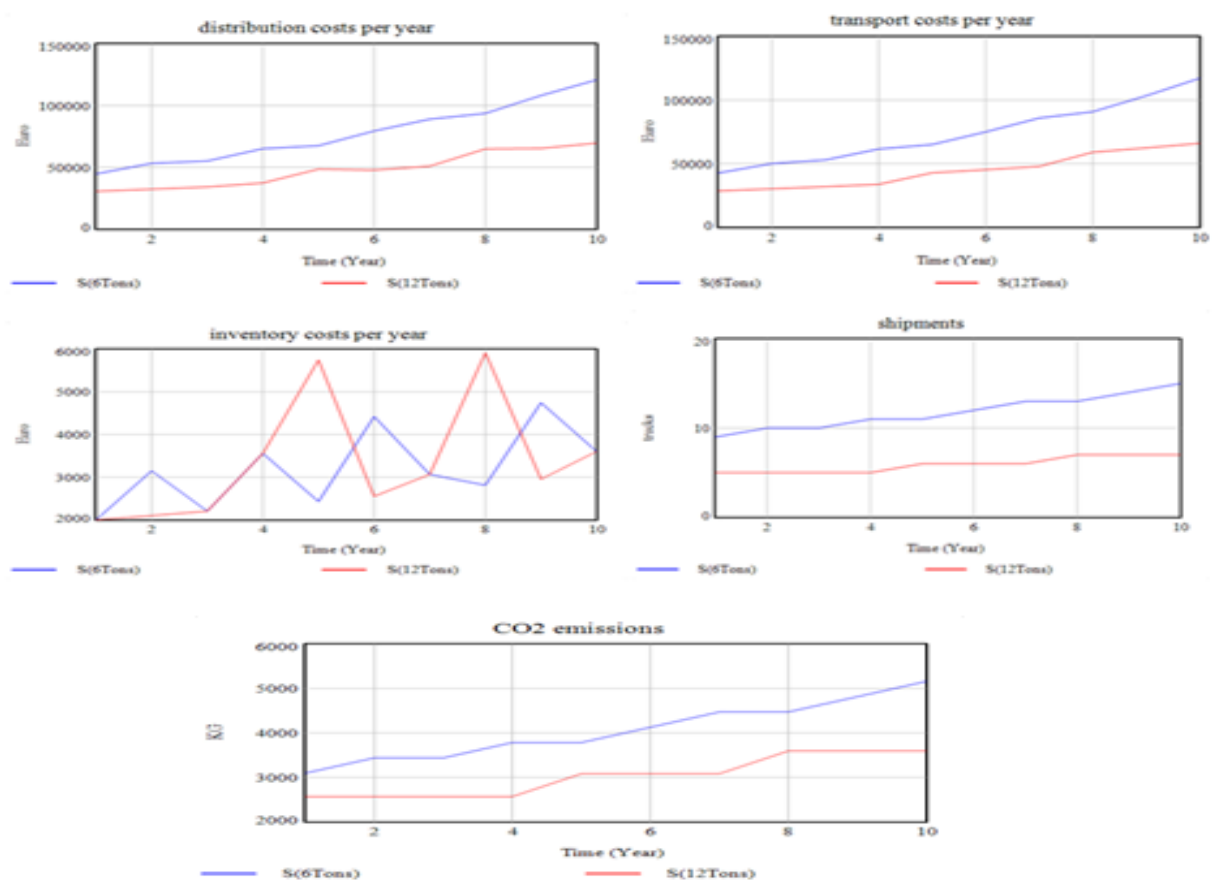

Figure 4. Development of distribution, transportation and inventory costs, as well as shipments and CO2 emissions based on truck loading capacity

The frequency of the order cycles is also a very important parameter in a distribution chain. To analyze its impact on distribution costs and customer satisfaction, we simulate the model with an order cycle frequency of 5,2 and 10 per year. The observed results (Figure 5) show that the order cycle frequency influences distribution costs and the percentage of customer satisfaction, as well as the quantity of emissions.
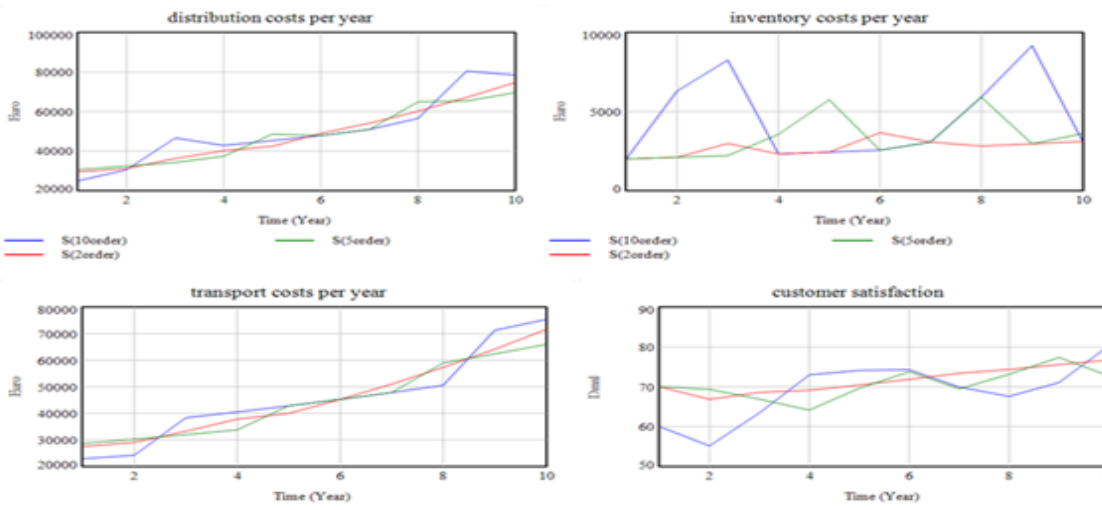

Z- scavedens)

necenter)

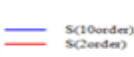

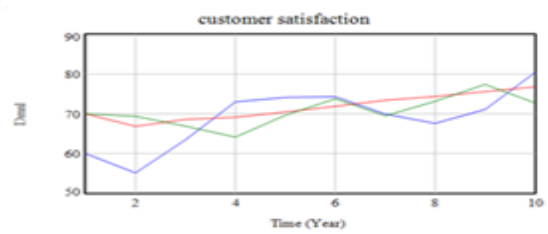

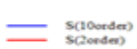

nec(rear)

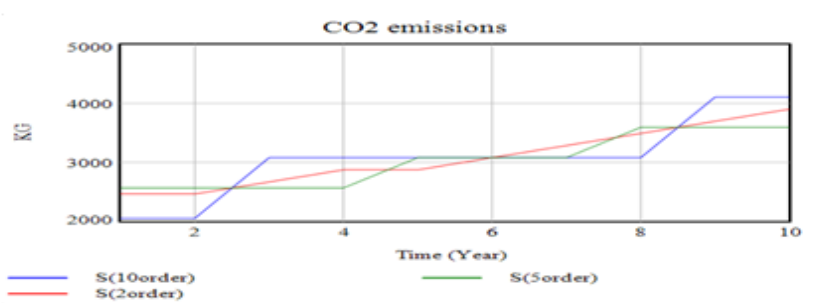

Figure 5. Development of distribution, inventory and transport costs, as well as customer satisfaction and CO2 emissions as a function of order cycle frequency 
In order to analyze the impact of the average speed on the distribution chain, we simulated the model with a speed of 80 and $40 \mathrm{~km} / \mathrm{h}$. The results (Figure 6) show that the distribution costs are very high with the speed of $40 \mathrm{~km} / \mathrm{h}$ and that comes down to the transport costs which are increased because of the increase in transport times. As for the emissions quantity, it is the same in both cases.
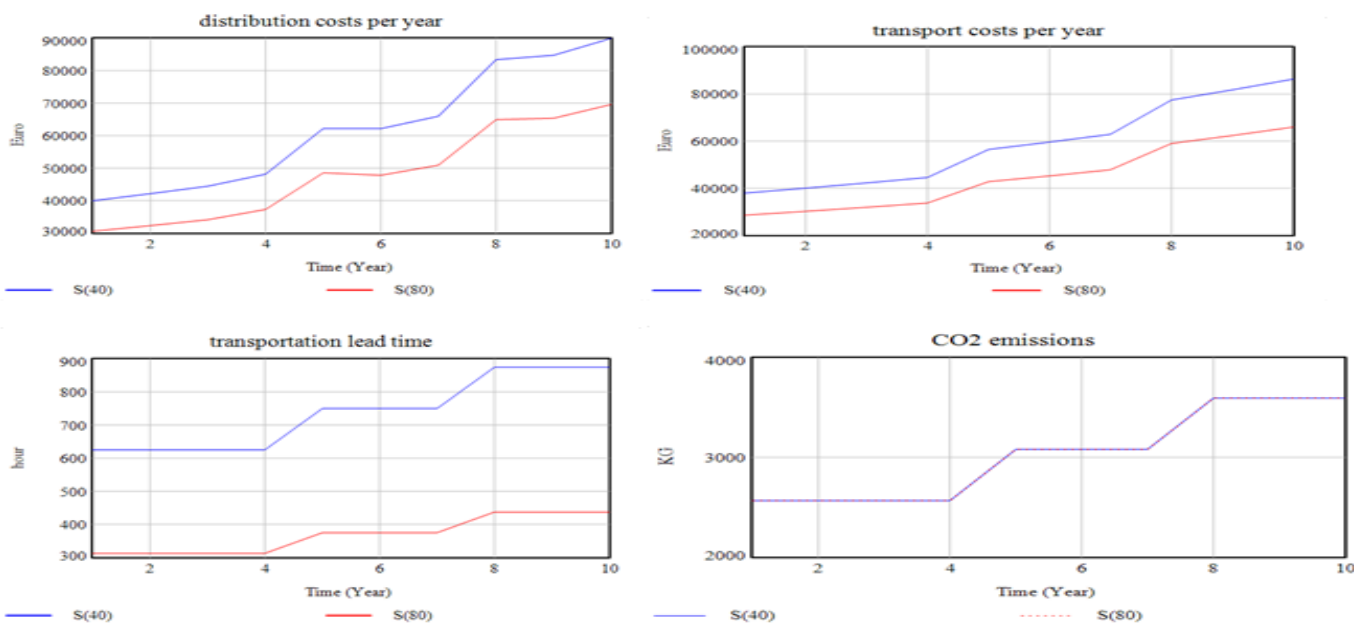

Figure 6. Development of distribution and transport costs, as well as transport times according to average speed

The average distance between the company and the customer is also a very important parameter that influences transport costs. We simulated the model with an average distance of 1000 and $500 \mathrm{~km}$. The results show that the distribution costs are very important for the average distance of $1000 \mathrm{~km}$ and that returns to the increase in transport costs because of the increase in the mileage covered by all the shipments. This has also caused an increase in emissions quantity.
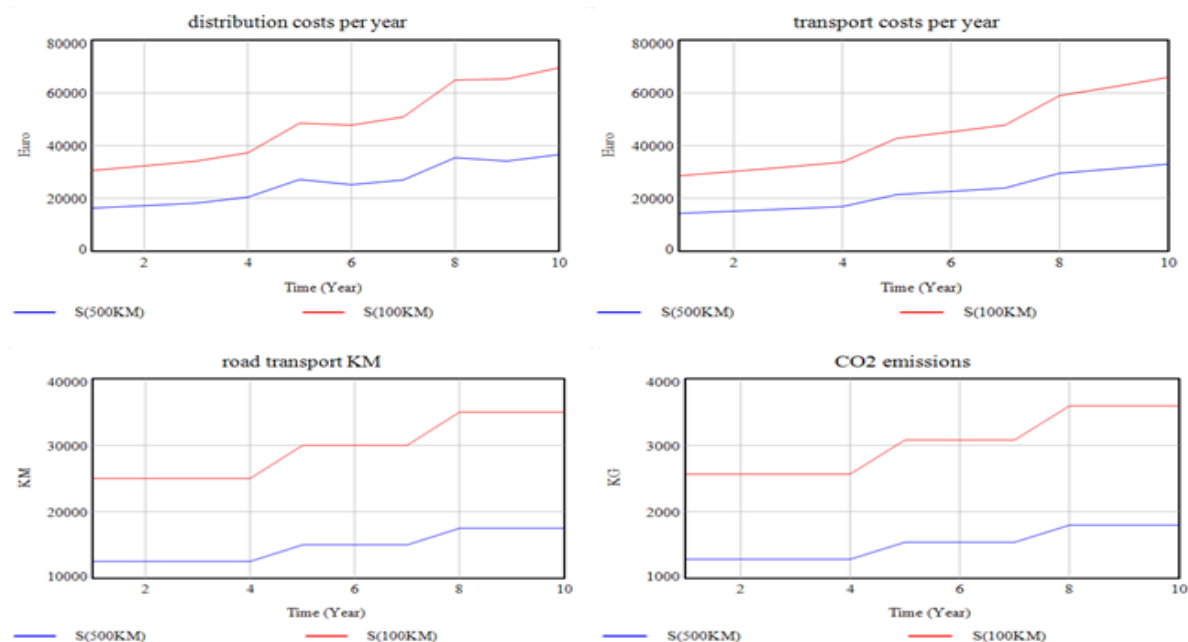

Figure 7. Development of distribution and transportation costs, as well as the mileage traveled by all shipments and $\mathrm{CO} 2$ emissions with the change in average distance

\section{Conclusion}

In this study, we presented a model of systems dynamics for the analysis of physical flows in a distribution logistics chain. The developed model makes it possible to understand and analyze the influence of logistics decisions and strategies on distribution costs.

The results of the tested scenarios show that logistic decisions and strategies taken at the supply chain level influence inventory and transport costs. The choice of the loading vehicles rate, their loading capacity, their order cycle frequency is generally taken lightly in the companies whereas they directly and significantly influence the distribution costs. 
The distances traveled depend on the distribution network and the strategic decisions of the companies as well as the speed of the shipments which depends on the road occupation rate also influence the distribution costs in a supply chain. The results show that the model is a good decision-support tool for calculating and analyzing transport and inventory costs. It is a full and straight forward model that helps understand the impact of logistics decisions on transportation costs, inventory costs, customer satisfaction and customer order. The model also addresses the environmental issues through the integration of a tax for $\mathrm{CO}_{2}$ emissions into transport costs.

The developed model can also be used to analyze various scenarios and perform various "what-if" analyzes, as well as to answer questions about the long-term operation of distribution chains.

The freight flow could also be influenced by other relevant market parameters (marketing strategies to make the business greener, financial aspects, etc.) that have been excluded in this model.

\section{References}

1. Abbas, K. A., Bell, M.G.H., (1994) System dynamics applicability to transportation modeling. Transportation Research Part A: Policy and Practice, 28, 373-390. Retrieved from: https://doi.org/10.1016/0965-8564(94)90022-1

2. Angerhofer, B.J., Angelides, M.C. (2000) System dynamics modelling in supply chain management: research review. In: Proceedings of the 2000 Winter Simulation Conference.

3. Aschauer, G., Gronalt, M., Mandl, C. (2015) Modelling interrelationships between logistics and transportation operations - a system dynamics approach. Management Research Review, 38, 505-539. Retrieved from: https://doi.org/10.1108/MRR-11-2013-0271

4. Bala, B.K., Arshad, F.M., Noh, K.M. (2017) System Dynamics, Springer Texts in Business and Economics. Springer Singapore, Singapore. Retrieved from: https://doi.org/10.1007/978-981-10-2045-2

5. Bhattacharjee, S., Cruz, J. (2015) Economic sustainability of closed loop supply chains: A holistic model for decision and policy analysis. Decision Support Systems, 77, 67-86. Retrieved from: https://doi.org/10.1016/j.dss.2015.05.011

6. De Jong, G., Gunn, H., Walker, W. (2004) National and International Freight Transport Models: An Overview and Ideas for Future Development. Transport Reviews, 24, 103-124. Retrieved from: https://doi.org/10.1080/0144164032000080494

7. Eddoug, K., Elhaq, S.L. (2015) Optimisation conjointe des coûts de transport et de stockage dans une chaîne logistique de distribution multi niveau: Une approche basée sur la simulation. Presented at the Xème Conférence Internationale: Conception et Production Intégrées, Maroc, p. 9.

8. Fiorello, D., Fermi, F., Bielanska, D. (2010) The ASTRA model for strategic assessment of transport policies. System Dynamics Review, 26, 283-290. Retrieved from: https://doi.org/10.1002/sdr.452

9. Franco, R.A.C., Yoshizaki, H.T.Y., Vieira, J.G.V. (2015) A system dynamics approach to logistics outsourcing policies and decisions. Production, 26, 285-302. Retrieved from: https://doi.org/10.1590/01036513.131413

10. Gacogne, V. (2003) Impact des coûts de transport sur les systèmes logistiques par une modèlisation en dynamique des systèmes- le modèle SANDOMA-. Ecole Nationale des Ponts et des Chaussées, France.

11. Ge, Y., Yang, J.-B., Proudlove, N., Spring, M. (2004) System dynamics modelling for supply-chain management: A case study on a supermarket chain in the UK. International Transactions in Operational Research, 11, 495-509. Retrieved from: https://doi.org/10.1111/j.1475-3995.2004.00473.x

12. Georgiadis, P., Vlachos, D. (2004) The effect of environmental parameters on product recovery. European Journal of Operational Research, 157, 449-464. Retrieved from: https://doi.org/10.1016/S0377-2217(03)00203-0

13. Georgiadis, P., Vlachos, D., Iakovou, E. (2005) A system dynamics modeling framework for the strategic supply chain management of food chains. Journal of Food Engineering, 70, 351-364. Retrieved from: https://doi.org/10.1016/j.jfoodeng.2004.06.030

14. Ghisolfi, V., Diniz Chaves, G. de L., Ribeiro Siman, R., Xavier, L.H. (2017) System dynamics applied to closed loop supply chains of desktops and laptops in Brazil: A perspective for social inclusion of waste pickers. Waste Management, 60, 14-31. Retrieved from: https://doi.org/10.1016/j.wasman.2016.12.018

15. Gonul Kochan, C., Nowicki, D.R., Sauser, B., Randall, W.S. (2018) Impact of cloud-based information sharing on hospital supply chain performance: A system dynamics framework. International Journal of Production Economics, 195, 168-185. Retrieved from: https://doi.org/10.1016/j.ijpe.2017.10.008

16. Jillson, K.R., Dozal-Mejorada, E.J., Ydstie, B.E. (2014) The Supply Chain as a Dynamical System. In: Pistikopoulos, E.N., Georgiadis, M.C., Dua, V. (Eds.), Process Systems Engineering. Wiley-VCH Verlag GmbH \& Co. KGaA, Weinheim, Germany, pp. 285-337. Retrieved from: https://doi.org/10.1002/9783527631209.ch41 
17. Lai, K., Ngai, E.W.T., Cheng, T.C.E. (2002) Measures for evaluating supply chain performance in transport logistics. Transportation Research Part E: Logistics and Transportation Review, 38, 439-456. Retrieved from: https://doi.org/10.1016/S1366-5545(02)00019-4

18. Poles, R. (2013) System Dynamics modelling of a production and inventory system for remanufacturing to evaluate system improvement strategies. International Journal of Production Economics, 144, 189-199. Retrieved from: https://doi.org/10.1016/j.ijpe.2013.02.003

19. Roy, S., Mukhopadhyay, S., Sengupta, P.P. (2008) Simulation Techniques on System Dynamics Modeling of Productioninventory Control Model. Journal of Information and Optimization Sciences, 29, 17-28. Retrieved from: https://doi.org/10.1080/02522667.2008.10699788

20. Ruijgrok, C. (2008) European Transport: Insights and Challenges. In: Brewer, A.M., Button, K.J., Hensher, D.A. (Eds.), Handbooks in Transport. Emerald Group Publishing Limited, pp. 29-46. Retrieved from: https://doi.org/10.1108/9780080435930-003

21. Sachan, A., Sahay, B.S., Sharma, D. (2005) Developing Indian grain supply chain cost model: a system dynamics approach. International Journal of Productivity and Performance Management, 54, 187-205. Retrieved from: https://doi.org/10.1108/17410400510584901

22. Sarimveis, H., Patrinos, P., Tarantilis, C.D., Kiranoudis, C.T. (2008). Dynamic modeling and control of supply chain systems: A review. Computers \& Operations Research, 35, 3530-3561. Retrieved from: https://doi.org/10.1016/j.cor.2007.01.017

23. Sidola, A., Kumar, P., Kumar, D. (2012) System dynamics investigation of information technology in small and medium enterprise supply chain. Journal of Advances in Management Research, 9, 199-207. Retrieved from: https://doi.org/10.1108/09727981211271940

24. Sterman, J.D. (2001) System Dynamics Modeling: Tools for Learning in a Complex World. California Management Review, 43.

25. Sudarto, S., Takahashi, K., Morikawa, K. (2017) Efficient flexible long-term capacity planning for optimal sustainability dimensions performance of reverse logistics social responsibility: A system dynamics approach. International Journal of Production Economics, 184, 179-192. Retrieved from: https://doi.org/10.1016/j.ijpe.2016.12.013

26. Thaller, C., Niemann, F., Dahmen, B., Clausen, U. (2017) Describing and explaining urban freight transport by System Dynamics. Transportation Research Procedia, 25, 1075-1094. Retrieved from: https://doi.org/10.1016/j.trpro.2017.05.480

27. Villa, S., Gonçalves, P., Arango, S. (2015) Exploring retailers' ordering decisions under delays: Exploring Retailer's Ordering Decisions under Delays. System Dynamics Review, 31, 1-27. Retrieved from: https://doi.org/10.1002/sdr.1527

28. Vlachos, D., Georgiadis, P., Iakovou, E. (2007) A system dynamics model for dynamic capacity planning of remanufacturing in closed-loop supply chains. Computers \& Operations Research, 34, 367-394. Retrieved from: https://doi.org/10.1016/j.cor.2005.03.005 